\title{
Irrigation, incision hydration, and eye pressurization with antibiotic-containing solution
}

\author{
This article was published in the following Dove Press journal: \\ Clinical Ophthalmology \\ 22 September 2015 \\ Number of times this article has been viewed
}

\author{
Kazuki Matsuura' \\ Ryu Uotani² \\ Shin-ichi Sasaki² \\ 'Department of Ophthalmology, \\ Nojima Hospital, Kurayoshi, Tottori, \\ 2Department of Ophthalmology, \\ Tottori University, Yonago, \\ Tottori, Japan
}

\section{Dear editor}

We congratulate Schelonka and SaBell for their recent article and would like to make a few comments on the application of their findings to the intracameral injection of antibiotics.

Schelonka and SaBell ${ }^{1}$ suggested that cataract surgeons who use vancomycin for irrigation should consider performing incision hydration and eye pressurization with an irrigating solution containing vancomycin, instead of using a plain balanced salt solution. In general, there are two methods for the administration of intracameral antibiotics.

The first method involves adding antibiotics to the irrigation bottle. However, many practitioners are skeptical about the effectiveness of this method. Because of the fast turnover in the anterior chamber, the intraoperatively secured antibiotic concentration may be insufficient. Furthermore, as Schelonka and SaBell ${ }^{1}$ indicated, even if the antibiotic solution in the irrigation bottle fills the anterior chamber during surgery, it is diluted by the time of pressurization and hydration.

The second method involves the injection of a small amount $(0.05-0.2 \mathrm{~mL})$ of highly concentrated solution at the end of surgery (the small-volume bolus injection method). However, small-volume bolus injections of antibiotics often disrupt self-sealing of the wound. The pressurization and hydration with plain balanced salt solution are often required, which dilutes the concentration of antibiotics in the anterior chamber. Thus, the final concentration of antibiotics becomes unclear and unreliable.

Compared with the widely conducted small-volume bolus injections, the technique of intracameral injection while irrigating, pressurizing, and hydrating the anterior chamber with a relatively large volume $(1.0-3.0 \mathrm{~mL})$ of solution (the large-volume irrigating injection method), is logical. ${ }^{2}$ This technique makes it possible to achieve a stable concentration of antibiotics, as the anterior chamber is replaced with diluted antibiotics and self-sealing is possible without any additional procedure.

In 2012, we reported favorable results in a retrospective survey on intracameral injection with large-volume irrigating injections using moxifloxacin (MFLX). ${ }^{3}$ Table 1 shows the results as of the end of 2014. Without MFLX, postoperative endophthalmitis occurred in 10 of 22,828 eyes. With MFLX, the occurrence of postoperative endophthalmitis significantly decreased to 3 of 47,058 eyes.

After intraocular lens (IOL) implantation and the removal of the viscosurgical device, the anterior chamber was irrigated with diluted MFLX $(100-500 \mu \mathrm{g} / \mathrm{mL})$ using a $5 \mathrm{~mL}$ hydration syringe. In practice, a cannula, through which solution was already flowing, was inserted via a side port, and the anterior chamber was irrigated 
Table I Incidence of postoperative endophthalmitis with or without intracameral moxifloxacin

\begin{tabular}{llll}
\hline $\begin{array}{l}\text { Without or with MFLX (antibiotic } \\
\text { concentration, method) }\end{array}$ & $\begin{array}{l}\text { Total } \\
\text { cases }(\mathbf{n})\end{array}$ & $\begin{array}{l}\text { Endophthalmitis } \\
\text { cases (n) }\end{array}$ & $\begin{array}{l}\text { P-value compared } \\
\text { to "without MFLX" }\end{array}$ \\
\hline Without MFLX & 22,828 & 10 & 0.001 \\
With MFLX (all) & 47,058 & 3 & 0.36 \\
With MFLX (I00-300 $\mu g / \mathrm{mL})$ & 10,705 & 1 & 0.001 \\
$(500 \mu g / \mathrm{mL})$ & 36,353 & 2 & 0.001 \\
With MFLX (flushing technique) & 32,996 & 1 & 0.001 \\
$(500 \mu g / \mathrm{mL}$, flushing technique) & 25,542 & 0 & \\
\hline
\end{tabular}

Notes: In all patients, the large-volume irrigating injection method was employed. The anterior chamber was irrigated with diluted MFLX (I00-500 $\mu g / \mathrm{mL})$. In patients for whom the BC flushing technique was used, the anterior chamber, including the area behind IOL, was intentionally irrigated through lifting the IOL edge. Two-tailed fisher's exact test was used for statistical analysis.

Abbreviations: MFLX, moxifloxacin; BC, bag and chamber; IOL, intraocular lens.

for several seconds. The edge of IOL was lifted, and the stream of solution was directed behind IOL. Once the anterior chamber had been irrigated for several seconds, the needle was removed while maintaining the flow of the solution. If necessary, incision hydration was added.

In our investigation, approximately $90 \%$ of the anterior chamber was replaced with the solution after approximately 10 seconds of irrigation. Because the anterior chamber was replaced with diluted antibiotics, a stable concentration could be attained and intraocular cleaning effects could be anticipated at the end of surgery.

Currently, vancomycin, cefuroxime, and MFLX are widely used as intracameral antibiotics. However, it is not realistic to conduct a prospective study to determine which of these is superior, as any of these solutions is likely to be highly effective and safe. In recent years, even in cases in which intracameral injection of antibiotics is not performed, the occurrence rate of postoperative endophthalmitis has significantly dropped. Furthermore, there are many factors involved in the onset of postoperative endophthalmitis, including perioperative disinfection or eye drops, the types of IOL, and surgical procedures. Therefore, an extremely large study sample would be required for accurate statistical analysis to compare all these factors.

Similarly, it is very difficult to compare differences between intracameral injections performed using the smallvolume injection method and those performed using the large-volume irrigating injection method.
As proposed by Schelonka and SaBell, ${ }^{1}$ irrigation, pressurization, and hydration using diluted antibiotics offer the same advantages as intracameral injections performed with the large-volume irrigating injection method which we proposed. Considered theoretically, even if its superiority is difficult to prove, the large-volume irrigating injection performed at the end of surgery makes more sense than the widely used current technique of intracameral injection performed using the small-volume injection method.

The method of irrigation, pressurization, and hydration using diluted antibacterial agents is worthy of consideration not only by practitioners who use antibiotics in the irrigating bottle but also by practitioners who perform intracameral injections using the small-volume bolus injection method at the end of surgery.

\section{Disclosure}

The authors report no conflicts of interest in this communication.

\section{References}

1. Schelonka LP, SaBell MA. Postcataract endophthalmitis prophylaxis using irrigation, incision hydration, and eye pressurization with vancomycin. Clin Ophthalmol. 2015;9:1337-1345. doi:10.2147/OPTH.S79119.

2. Matsuura K, Suto C, Akura J, Inoue Y. Bag and chamber flushing: a new method of using intracameral moxifloxacin to irrigate the anterior chamber and the area behind the intraocular lens. Graefes Arch Clin Exp Ophthalmol. 2013;251(1):81-87. doi:10.1007/s00417-012-2098-1.

3. Matsuura K, Miyoshi T, Suto C, Akura J, Inoue Y. Efficacy and safety of prophylactic intracameral moxifloxacin injection in Japan. J Cataract Refract Surg. 2013;39(11):1702-1706. doi:10.1016/j.jcrs.2013.05.036. 


\section{Authors' reply}

\section{Lee P Schelonka'}

Margaret A SaBell ${ }^{2}$

'Department of Ophthalmology, ${ }^{2}$ Department of Infection Control, Kaiser Permanente Lone Tree Medical Offices, Lone Tree, Denver, CO, USA

\section{Correspondence: Lee P Schelonka}

Department of Ophthalmology, Kaiser Permanente Lone Tree Medical Offices, 10240 Park Meadows Drive, Lone Tree, Denver, CO 80I24, USA

Tel + I 303649543 I

$\mathrm{Fax}+\mathrm{I} 3036495405$

Email leeschelonka@msn.com

\section{Dear editor}

We agree with Matsuura et al that bag and chamber flushing with moxifloxacin (MFLX) shares the pharmacokinetic advantages of vancomycin irrigation, incision hydration and eye pressurization. The crucial point is to reliably place a sufficient concentration of antibiotics in the anterior chamber at the end of surgery. Matsuura's very low rate of postcataract endophthalmitis using MFLX bag and chamber flushing is commendable. In Japan, the high prevalence of Enterococcus faecalis endophthalmitis ${ }^{1}$ may make MFLX a more effective prophylaxis antibiotic than vancomycin. However, our concerns over the high prevalence of MFLX-resistant coagulase-negative Staphylococcus endophthalmitis in the $\mathrm{USA}^{2}$ and the safety issues of cefuroxime anaphylaxis ${ }^{3,4}$ led us to continue using vancomycin. For the many surgeons who already irrigate with vancomycin, ${ }^{5}$ using the irrigating solution for eye pressurization and incision hydration (instead of plain balanced salt solution) is likely to increase the efficacy of endophthalmitis prophylaxis.

\section{Disclosure}

The authors report no conflicts of interest in this communication.

\section{References}

1. Matsuura K, Miyoshi T, Suto C, Akura J, Inoue Y. Efficacy and safety of prophylactic intracameral moxifloxacin injection in Japan. J Cataract Refract Surg. 2013;39(11):1702-1706.

2. Harper T, Miller D, Flynn HW Jr. In vitro efficacy and pharmacodynamic indices for antibiotics against coagulase-negative Staphylococcus endophthalmitis isolates. Ophthalmology. 2007;114(5):871-875.

3. Villada JR, Vicente U, Javaloy J, Alio JL. Severe anaphylactic reaction after intracameral antibiotic administration during cataract surgery. J Cataract Refract Surg. 2005;31(3):620-621.

4. Moisseiev E, Levinger E. Anaphylactic reaction following intracameral cefuroxime injection during cataract surgery. J Cataract Refract Surg. 2013;39(9):1432-1434.

5. Leaming D. Results of the 2012 ASCRS Cataract Surgery Survey; 2015. Available from: www.analeyz.com/NEWanaleyz $\% 20$ ASCRS $\% 202012$. htm. Accessed August 26, 2015.

Dove Medical Press encourages responsible, free and frank academic debate. The content of the Clinical Ophthalmology 'letters to the editor' section does not necessarily represent the views of Dove Medical Press, its officers, agents, employees, related entities or the Clinical Ophthalmology editors. While all reasonable steps have been taken to confirm the content of each letter, Dove Medical Press accepts no liability in respect of the content of any letter, nor is it responsible for the content and accuracy of any letter to the editor.

\section{Publish your work in this journal}

Clinical Ophthalmology is an international, peer-reviewed journal covering all subspecialties within ophthalmology. Key topics include: Optometry; Visual science; Pharmacology and drug therapy in eye diseases; Basic Sciences; Primary and Secondary eye care; Patient Safety and Quality of Care Improvements. This journal is indexed on
PubMed Central and CAS, and is the official journal of The Society of Clinical Ophthalmology (SCO). The manuscript management system is completely online and includes a very quick and fair peer-review system, which is all easy to use. Visit http://www.dovepress.com/ testimonials.php to read real quotes from published authors. 